\title{
SISTEM PERINGATAN DINI KETAHANAN PERBANKAN \\ TERHADAP GUNCANGAN INTERNAL DAN EKSTERNAL DENGAN MODEL ARTIFICAL NEURAL NETWORK
}

\author{
Azmia Ulfah \\ azmiaulfah@gmail.com \\ Perbanas Institut Jakarta \\ Muhammad Iqbal \\ iqbal@perbanas.id \\ Perbanas Institut Jakarta \\ Selamet Riyadi \\ selametriyadi@gmail.com \\ Perbanas Institut Jakarta
}

\begin{abstract}
Financial stability system is a complex system which formed and associated with monetary policy and an economic in the country. Therefore we need model to be able to quickly and accurately predict the instability of financial system may occur.This research is aim to built Artifical Neural Network (ANN) model as a early warning system for banking failure prediction based a bank compliance. This research combine internal and external factor affect banking performance as a indicator. The result of this research proved ANN could be use as an alternative method to detect the level of sustainability of a banks.
\end{abstract}

Kata Kunci : stabilitas sistem keuangan, early warning system, artifical neural network, perbankan

\section{Pendahuluan}

Stabilitas sistem keuangan merupakan salah satu tujuan yang ingin dicapai oleh bank sentral suatu negara agar perekonomian negaranya dapat berjalan dengan baik. Bank Indonesia menerjemahkan stabilitas sistem keuangan sebagai suatu kondisi yang mendukung pertumbuhan ekonomi melalui mekanisme ekonomi dan pengelolaan risiko yang berfungsi dengan baik. Selain dari itu, stabilitas keuangan juga berkaitan dengan keadaan ekonomi makro dan stabilitas moneter sehingga bila terjadi gunjangan pada perekonomian, baik sektor riilmaupun moneter, akan menyebabkan instabilitas sistem keuangan.

Salah satu contoh instabilitas sistem keuangan terburuk di Indonesia terjadi pada tahun 1997-1998. Berawal dari krisis moneter pada awal juli 1997 dan berlanjut hingga tahun 1998. Sebagai akibat dari krisis moneter, Bank Indonesia mengubah sistem nilai tukar rupiah terhadap valuta asing dari sebelumnya managed floating menjadi free floating yang berarti nilai tukar dikendalikan oleh mekanisme pasar uang (Novaly, 2014). Kemudian memberikan efek domino pada sektor keuangan sebagai berikut: 


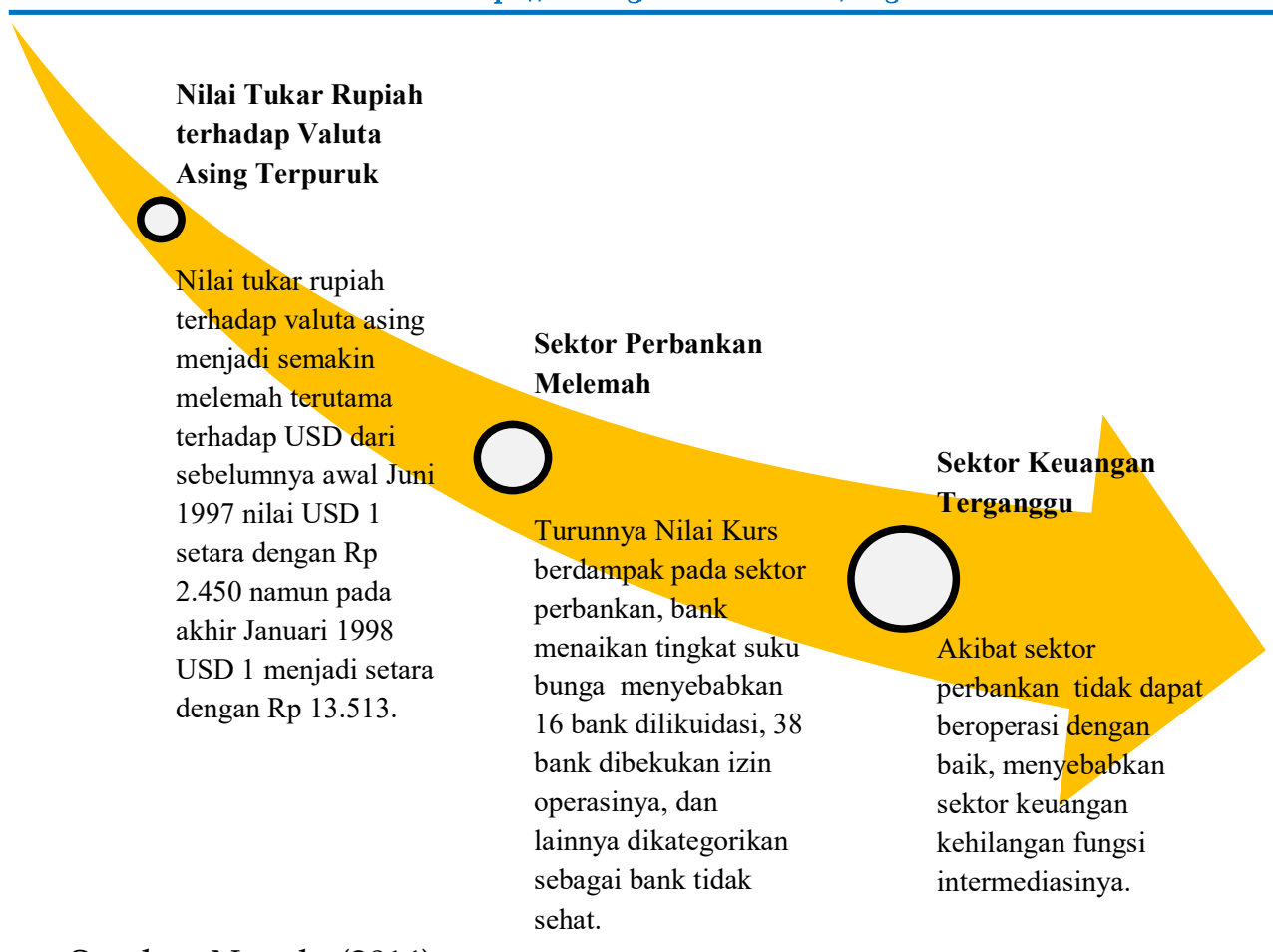

Sumber: Novaly (2014)

Berdasarkan Kajian Stabilitas Keuangan Bank Indonesia tahun 2014 apabila dilihat dari pangsa pasarsistem keuangan 2013, industri perbankan masih memegang peranan paling dominan pada sektor keuangan yaitu dengan persentase $78,5 \%$ jauh lebih tinggi dibanding lembaga keuangan lainnya. Sehingga kestabilan pada dunia perbankan cukup memberikan andil pada stabilitas sistem keuangan. Stabilitas sistem keuangan tidak dapat tercapai apabila tidak ada keseimbangan antara penyedia dana (surplus unit) dan penerima dana (defisit unit). Sehingga pasar menjadi bergejolak, penabung tidak lagi mau menabung, potensi peminjam berkurang karena suku bunga yang tidak stabil dan beberapa akibat lain yang dapat menimbulkan gangguan stabilitas sistem keuangan (Sitompul, 2014).

Pada masalah perbankan di Asia rasio-rasio keuangan seperti kecukupan modal, manajemen kredit dan efisiensi operasi telah umum digunakan sebagai indikator kinerja pada masalah perbankan di Asia (Ozkan-Gunay dan Ozkan, 2007). Sejalan dengan itu Hosni (2014) juga menyimpulkan terjadinya krisis perbankan tidak lepas dari peran penting variabel akuntansi, yaitu rasio-rasio keuangan seperti rendahnya Return on Assets (ROA), rendahnya non-performing loan (NPL) dan rendahnya biaya (rasio pendapatan biaya) berhubungan dengan probabilitas tinggi dari krisis karena rasio-rasio tersebut memberikan kesalahan sinyal yang rendah dan presentase yang tinggi atas ketepatan prediksi krisis.

Namun faktor eksternal perbankan seperti perekonomian suatu negara juga dapat mempengaruhi kinerja bank, seperti yang dinyatakan Hosni (2014) bahwa banyak para penulis menyetujui bahwa krisis perbankan biasanya didahului fluktuasi besar dalam nilai tukar riil. Ketidakstabilan pada nilai tukar, baik secara langsung yaitu ketika terjadi mismatch antara aset dan kewajiban bank, atau secara tidak langsung yaitu ketika tingkat volatilitas menyebabkan kerugian pada counterparty bank. Pada perbankan Indonesia berdasarkan SE BI No. 13/24/DPNP Tahun 2011 faktor eksternal yang dapat mempengaruhi kestabilan bank adalah perubahan kondisi ekonomi yang diakibatkan oleh perubahan regulasi sehingga mempengaruhi nilai tukar dan tingkat suku bunga. 
Seiring semakin meningkatnya kebutuhan bank untuk mengantisipasi risiko, telah banyak penelitian yang bertujuan untuk menguji seluruh faktor yang mempengaruhi perbankan kedalam suatu metode untuk memprediksi tingkat kegagalan bank atau yang biasa dikenal dengan early warning system. Berbagai penelitian dengan berbagai indikator dan early warning system yang berbeda telah dilakukan untuk mengetahui dan menemukan model yang sesuai untuk perbankan agar dapat menghindari risiko dan krisis. Seperti, Hosni (2014) dengan variabel dependennya adalah ICBt dan variabel independen dari berbagai kategori yaitu makroekonomi, keuangan, akuntansi, dan variabel eksternal seperti penanaman modal asing secara langsung menggunakan model BMA (Bayesian Model Averaging). Sementara Huang, dkk (2010) menggunakan model KMV dengan menggunakan data saham untuk menghitung default point dan default distance pada tiga Bank di China.

Selain itu juga muncul modelArtifical Neural Network (ANN) merupakan model yang telah digunakan dalam literatur ekonomi baik dalam klasifikasi agen ekonomi maupun prediksi time series, namun secara luas digunakan untuk prediksi kebangkrutan sementara sedikit sekali aplikasi fokus pada krisis keuangan (Sekmen dan Kurkcu, 2014). Sekmen dan Kurkcu (2014) menemukan bahwa model ANN merupakan model yang baik, karena dapat menangkap pola yang lebih nonlinear dan disembunyikan dalam data, sehingga dapat mengarahkan kepada peningkatan kinerja.

Berdasarkan pemaparan diatas bisa dilihat bahwa banyak sekali faktor yang dapat mempengaruhi kinerja dan kesehatan bank, maka diperlukan penelitian lebih lanjut mengenai indikator yang dapat mempengaruhi kinerja bank di Indonesia dengan model yang tengah berkembang, salah satu yang dapat diaplikasikan adalah model ANN.Penelitian ini bertujuanmembangun model ANN (Artifical Neural Network) untuk memprediksi kegagalan perbankan berdasarkan tingkat kepatuhan perbankan atas perubahan faktor internal dan eksternal bank. Sebagai salah satu alternatif pendekatan, model ANN yang dibangun diharapkan memiliki tingkat akurasi yang tinggi dalam menditeksi peringatan dini atas kegagalan suatu bank.

\section{Kajian Literatur}

Keadaan moneter dan perekonomian termasuk dalam faktor penentu stabilitas sistem keuangan suatu negara, karena menurut definisi Bank Indonesia stabilitas sistem keuangan merupakan keadaan dimana mekanisme ekonomi dapat mendukung pertumbuhan ekonomi melalui penetapan harga, alokasi dana dan pengelolaan risiko yang berfungsi dengan baik.Menurut Australian National Bank dikutip dari Alawode dan Al Sadek (2008) mendefinisikan stabilitas sistem keuangan sebagai proses dimana perantara keuangan, pasar dan infrastruktur pasar memfasilitasi kelancaran arus dana penabung dan investor dengan demikian membantu mendorong pertumbuhan kegiatan ekonomi. Sistem keuangan meliputi perantara keuangan baik itu bank maupun nonbank, pasar modal, maupun infrastruktur keuangan berupa pembayaran dan sistem penyelesaian keuangan(Alawode dan Al Sadek, 2008).Bank sentral suatu negara merupakan pihak yang berperan dalam pengawas dan pengatur stabilitas sistem keuangan. Didalam mengatur stabilitas keuangan bank sentral perlu memperhatikan institutsi-institusi keuangan terutama perbankan. Perbankan sebagai lembaga intermediasiantara pihak yang memiliki dana dan pihak yang mebutuhkan dana menjadi sangat menentukan keadaan moneter (Santoso dan Batunanggar, 2007).

Bank Indonesia menyatakan bahwa kepatuhan bank dapat menjadi salah satu parameter tingkat kesehatan. Pengawasan terhadap tingkat kepatuhan bank memastikan bahwa bank telah beroperasi dan dikelola dengan baik dan benar berdasarkan prinsip kehati-hatian. Maka dapat dikatakan bahwa bank telah memenuhi kepatuhan bank maka 
bank tersebut telah bersikap hati-hati dalam operasinya dan berperan dalam menjaga kestabilan sistem keuangan sebagai institusi keuangan yang berperan besar.

Bank Indonesia menetapkan beberapa rasio yang harus dijaga besaran angkanya sebagai salah satu bentuk kepatuhan bank. Pada penelitian ini penulis menggunakan kepatuhan pada rasio keuangan LDR, NPL, CAR dan PDN. Berdasarkan peraturan Bank Indonesia yaitu LDR yang harus dijaga oleh bank berada pada kisaran 85\%-100\%, NPL maksimal 5\%, CAR maksimal 8\% dan PDN 20\% dari modal.

Berdasarkan PBI No. 13/1/PBI/2011 tentang Penilaian Tingkat Kesehatan Bank Umum, penilaian risiko pada suatu perbankan meliputi segala risiko inheren dan kualitas penerapan manajemen risiko dalam kegiatan operasional bank. Setiap kegiatan operasional bank perlu dilakukan penilaian risiko atas delapan risiko, yaitu: risiko kredit, risiko pasar, risiko likuiditas, risiko operasional, risiko hukum, risiko stratejik, risiko kepatuhan, risiko reputasi.

Adapun komponen risiko-risiko perbankan yang akan digunakan dalam penelitian ini ada tiga, yaitu: risiko kredit, risiko pasar dan likuditas.Risiko kredit merupakan risiko yang disebabkan ketidakmampuan debitur untuk memebuhi kewajiban kepada bank (Purnamasari dan Mimba, 2014). Apabila risiko ini terjadi maka bank akan kehilangan dananya sehingga mengurangi pendapatan bank dan menambah beban kredit macet bank. Pada lampiran SE BI No. 13/24/DPNP Tahun 2011, salah satu pengukuran dalam risiko kredit adalah dengan rumus :

$$
N P L=\frac{\text { KreditBermasala }}{\text { TotalKredit }}
$$

Risiko pasaradalah risiko yang timbul akibat adanya perubahan pada struktur pasar seperti, tingkat suku bunga dan nilai tukar mata uang internasional yang tentunya dapat meningkatkan potensi kerugian bank (Fitri dkk, 2012). Rasio yang dapat digunakan dalam menghitung risiko pasar pada SE BI 13/24/DPNP Tahun 2011 yaitu rasio posisi devisa neto bank yang menggambarkan posisi kepemilikan valuta asing suatu bank, dengan rumus:

\section{$\frac{P D N}{\text { TotalModal }}$}

Risiko likuiditas adalah risiko yang timbul saat Bank tidak mampu memenuhi kewajibannya yang telah jatuh tempo baik dari sumper pendanaan arus kas maupun dari aset likuid berkualitas tinggi yang dapat diagunkan, tanpa mengganggu aktivitas dan kondisi keuangan Bank. (Purnamasari dan Mimba, 2014). Rasio likuiditas yang digunakan pada penelitian ini adalah Rasio LDR (Loan to Deposit Ratio). LDR dapat menggambarkan kualitas manajemen bank, karena rasio ini berkaitan dengan manajemen likuiditas dan kinerja perbankan dalam memberikan kredit dari sumber dana kredit yaitu dana pihak ketiga (Kammoun dan Charfi, 2013). Rasio likuiditas lainnya yang digunakan adalah rasio kas terhadap total aset rasio ini jarang digunakan pada perhitungan likuiditas bank, rasio ini menggambarkan berapa bagian dari aset yang memiliki sifat yang sangat likuid.

$$
\begin{aligned}
& L D R=\frac{\text { TotalKredit }}{\text { TotalDanaPi akKetiga }} \\
& \text { Cas toAssetRatio }=\frac{\text { TotalKas }}{\text { TotalAset }}
\end{aligned}
$$


Rentabilitas atau profitabilitas merupakan suatu pengukuran kemampuan atau pencapaian suatu perusahaan untuk memperoleh laba selama periode tertentu. Rentabilitas adalah kemampuan bank dalam menambah laba dan efisien usaha yang dicapai (Purnamasari dan Mimba, 2014). Bank sebagai pemberi kredit akan memaksimalkan setiap kredit yang diberikan untuk mendapatkan keuntungan dari setiap pemberian kredit tersebut. Bagi bank,ukuran profitabilitas lebih penting daripada ukuran pertumbuhan aset. Sehingga kondisi yang dibutuhkan untuk keamanan seluruh sistem berhubungan dengan profitabilitas, yang diukur oleh return on equity (ROE) atau return on assets(ROA) (Kammaoun dan Charfi, 2013).Selain ROA dan ROE pada penelitian ini juga menggunakan net interest margin (NIM)dan rasio antara beban operasional terhadap pendapatan operasional (BOPO) untuk mengukur keefisienan operasional bank.NIM dan BOPO menunjukan kemampuan bank dalam menghasilkan pendapatan bunga dari hasil operasional dan pengelolaan biaya operasional terhadap pendapatan operasional (Aini, 2013).

Berdasarkan PBI No. 13/1/PBI/11 faktor permodalan yang perlu diperhatikan bank dalam tingkat kesehatan bank adalah kecukupan modal dan pengelolaan permodalan. Kecukupan modal bank dihitung dengan rasio CAR (Capital Adequacy Ratio). CAR memiliki perkembangan metode perhitungan berdasarkan Basel I CAR dapat dihitung dengan rumus:

$$
\text { CAR }=\frac{\text { TotalModal }}{\text { TotalATMR }}
$$

dan berdasarkan Basel II rumus CAR adalah:

$$
C A R=\frac{\text { Modal }}{\text { RisikoKredit }+ \text { RisikoOperasional }+ \text { RisikoPasar }}
$$

Tingkat kestabilan bank tidak hanya dipengaruhi oleh faktor internal bank namun juga faktor eksternal, terutama pengaruh dari perubahan keadaan perekonomian suatu negara. Dalam pembentukan model early warning systemmenurut Yang dan Tkachenko (2012),model prediksi akan mendekati kondisi yang terjadi apabila memasukan variabel makroekonomi pada model prediksi, terlepas dari perubahan-perubahan yang mungkin terjadi akibat dari lingkaran kegiatan ekonomi yang kompleks. Bank Indonesia menyatakan beberapa faktor yang dapat mempengaruhi perbankan dan digunakan pada peneltian ini antara lain perubahan kondisi ekonomi, tingkat suku bunga dan nilai tukar.

Perubahan kondisi ekonomi dapat dilihat dari PDB riil suatu negara. PDB riil atau disebut juga dengan PDB atas dasar harga konstan menunjukan nilai tambah barang dan jasa yang dihitung menggunakan harga yang berlaku pada tahun dasar tertentu yang telah ditetapkan sehingga PDB riil dapat digunakan untuk mengetahui pertumbuhan ekonomi dari tahun ke tahun (BPS, 2015). Purba (2013) menyatakan pertumbuhan ekonomi yang diproksi dengan Produk Domestik Bruto (PDB) sebagai alat ukur untuk melihat struktur perekonomian sebagai indikator suatu perekonomian tumbuh atau tidak. Apabila tingkat kegiatan ekonomi yang dicapai lebih tinggi daripada tingkat kegiatan ekonomi yang dicapai pada periode sebelumnya maka dapat dikatakan bahwa perekonomian negara mengalami pertumbuhan.

Perubahan kondisi ekonomi juga dikaitkan dengan inflasi suatu negara. Inflasi bukan hanya keadaan tinggi-rendahnya tingkat harga melainkan proses dari suatu peristiwa menurunnya nilai mata uang secara berkelanjutan, juga sering diartikan dengan meningkatnya jumlah uang beredar. Persediaan uang dianggap sebagai salah satu penyebab meningkatnya harga. (Sutono dan Kefi, 2013). 
3. Metode

Pada penelitian ini penulis mengajukan ANN sebagai metode early warning system untuk mendeteksi ketahanan perbankan yang dilihat dari tingkat kepatuhan bank. ANN (Aritifical Neural Network) merupakan suatu metode yang sering digunakan dalam membuat model dan peramalan suatu masalah, antara lain membuat model dan peramalan harga saham, nilai tukar, tingkat suku bunga dan sebagainya (Sekmen dan Kurkcu, 2014). Sebelumnya Ozkan-Gunay dan Ozkan (2007) menyatakan bahwa metode ANN lebih efektif dibandingkan MDA (Multivariat Discriminant Analysis) atau metode early warning sytem lainnya, keistimewaan ANN terletak pada kesegaran metode, multimodel distribution, dan adaptive model adjustment, sementaradiscriminant analysis (DA) memang telah populer digunakan dalam teknik prediksi kebangkrutan namun mengalami kendala pada metode dan statistik sehingga mengalami kesulitan dalam kegunaan praktis.

Sekmen dan Kurkcu (2014) menggunakanmultilayer neural network atau disebut dengan Multi-Layer Perceptron (MLP). MLP merupakan model ANN yang paling sering digunakan. Model MLP digambarkan sebagai berikut:



Gambar 1. Rancangan Multi Layer Perceptron (Sekmen dan Kurkcu, 2014)

Menurut Sekmen dan Kurkcu (2014) model Neural Network ini secara sempurna saling terhubung mulai dari input layer menuju output layer sehingga informasi beredar dari satu layer menuju layer lain tanpa kemungkinan kembali kebelakang. Selain input dan output layer dalam MLP juga terdapat intermediate layer yang disebut dengan hidden layer. Hingga saat ini belum ada teori yang mendasari penentuan jumlah hidden layer dan perceptron yang digunakan pada tiap metode prediksi, sehingga penulis menentukan banyak hidden layer dan perceptron yang digunakan sesuai dengan percobaan yang memberikan hasil terbaik.

Didalam keperluan penelitian penulis membagi sampel menjadi dua bagian yaitu bank yang tidak memenuhi kepatuhan rasio-rasio perbankan diistilahkan dengan Not Compliant dan bank yang memenuhi kepatuhan rasio-rasio perbankan dengan Compliant. Dengan 16 variabel independen merupakan variabel faktor internal bank berdasarkan komponen metode RBBR kecuali komponen GCG karena ketidaklengkapan data yang dibutuhkan dan faktor eksternal bank sebagai berikut: 
Tabel 1.

Daftar Variabel Penelitian dalam Pembentukan Model ANN

\begin{tabular}{lll}
\hline \multicolumn{1}{c}{ Faktor } & \multicolumn{1}{c}{ Variabel } & \multicolumn{1}{c}{ Indikator } \\
\hline Internal (RBBR) & Profil Risiko (Risk Profile) & \multicolumn{1}{c}{ PDN } \\
& \multicolumn{1}{c}{ Risiko Pasar } & LDR, Cash to Asset Ratio \\
& \multicolumn{1}{c}{ Risiko Likuiditas } & NPL \\
& Rentabilitas (Earnings) & NIM, ROE, ROA, BOPO \\
& Modal (Capital) & CAR \\
Eksternal & Nilai Kurs & USD, SGD, JPY, AUD \\
(Makroekonomi) & Tingkat Suku Bunga & SBI \\
& Inflasi & IHK \\
& Pertumbuhan Ekonomi & PDB
\end{tabular}

Penelitian ini dilakukan dengan objek penelitian bank persero dan devisa dari 4 bank persero dan 35 bank devisa, yang menjadi objek penelitian ini adalah 15 bank yaitu 4 bank persero dan 11 bank devisa dengan periode penelitian adalah 2007-2014. Data yang digunakan seluruhnya merupakan data sekunder. Data rasio-rasio keuangan bank diambil dari laporan keuangan bank dari webiste masing-masing bank, data tingkat suku bunga, inflasi, dan nilai mata uang diambil dari webiste Bank Indonesia, dan data PDB diambil dari data BPS yang merupakan perhitungan PDB atas dasar harga konstan tahun 2000 per tahun 2007-2014.

\section{Hasil dan Pembahasan}

Penelitian ini menggunakan ANN sebagai metode pendeteksi kepatuhan bank atas perubahan kondisi internal maupun eksternal bank. Didalam pembentukan model dilakukan beberapa percobaan untuk menemukan model terbaik. Dari percobaan yang telah dilakukan diputuskan untuk menggunakan 1 hidden layer dengan 16 perceptron. Hasil dari model yang penulis bentuk dengan tingkat kepercayaan 93\%, berhasil mendeteksi 80\% bank yang patuh dan 93\% bank yang tidak patuh dengan benar.Tabel 2 merangkum hasil prediksi yang dihasilkan oleh model ANN. 
Tabel 2.

Hasil Prediksi dengan Model ANN (Artifical Neural Network)

\begin{tabular}{|c|c|c|c|c|c|c|c|c|}
\hline Bank & 2007 & 2008 & 2009 & 2010 & 2011 & 2012 & 2013 & 2014 \\
\hline \multirow[b]{2}{*}{1} & Not & Not & Not & Not & Not & Not & Not & Not \\
\hline & Compliant & Compliant & Compliant & Compliant & Compliant & Compliant & Compliant & Compliant \\
\hline \multirow{2}{*}{2} & & Not & Not & Not & Not & Not & Not & Not \\
\hline & Compliant & Compliant & Compliant & Compliant & Compliant & Compliant & Compliant & Compliant \\
\hline 3 & $\begin{array}{c}\text { Not } \\
\text { Compliant }\end{array}$ & $\begin{array}{c}\text { Not } \\
\text { Compliant }\end{array}$ & $\begin{array}{c}\text { Not } \\
\text { Compliant }\end{array}$ & $\begin{array}{c}\text { Not } \\
\text { Compliant }\end{array}$ & $\begin{array}{c}\text { Not } \\
\text { Compliant }\end{array}$ & $\begin{array}{c}\text { Not } \\
\text { Compliant }\end{array}$ & Compliant & Complian \\
\hline 4 & Compliant & Compliant & Compliant & Compliant & Compliant & Compliant & Compliant & Compliant \\
\hline 5 & $\begin{array}{c}\text { Not } \\
\text { Compliant }\end{array}$ & $\begin{array}{c}\text { Not } \\
\text { Compliant }\end{array}$ & $\begin{array}{c}\text { Not } \\
\text { Compliant }\end{array}$ & $\begin{array}{c}\text { Not } \\
\text { Compliant }\end{array}$ & $\begin{array}{c}\text { Not } \\
\text { Compliant }\end{array}$ & $\begin{array}{c}\text { Not } \\
\text { Compliant }\end{array}$ & $\begin{array}{c}\text { Not } \\
\text { Compliant }\end{array}$ & $\begin{array}{c}\text { Not } \\
\text { Compliant }\end{array}$ \\
\hline 6 & $\begin{array}{c}\text { Not } \\
\text { Compliant }\end{array}$ & Compliant & Compliant & Compliant & Compliant & Compliant & Compliant & Compliant \\
\hline 7 & Compliant & $\begin{array}{c}\text { Not } \\
\text { Compliant }\end{array}$ & $\begin{array}{c}\text { Not } \\
\text { Compliant }\end{array}$ & $\begin{array}{c}\text { Not } \\
\text { Compliant }\end{array}$ & $\begin{array}{c}\text { Not } \\
\text { Compliant }\end{array}$ & Compliant & Compliant & Compliant \\
\hline 8 & Compliant & Compliant & $\begin{array}{c}\text { Not } \\
\text { Compliant }\end{array}$ & $\begin{array}{c}\text { Not } \\
\text { Compliant }\end{array}$ & $\begin{array}{c}\text { Not } \\
\text { Compliant }\end{array}$ & $\begin{array}{c}\text { Not } \\
\text { Compliant }\end{array}$ & Compliant & $\begin{array}{c}\text { Not } \\
\text { Compliant }\end{array}$ \\
\hline 9 & $\begin{array}{c}\text { Not } \\
\text { Compliant }\end{array}$ & $\begin{array}{c}\text { Not } \\
\text { Compliant }\end{array}$ & $\begin{array}{c}\text { Not } \\
\text { Compliant }\end{array}$ & $\begin{array}{c}\text { Not } \\
\text { Compliant }\end{array}$ & $\begin{array}{l}\text { Not } \\
\text { Compliant }\end{array}$ & $\begin{array}{c}\text { Not } \\
\text { Compliant }\end{array}$ & $\begin{array}{c}\text { Not } \\
\text { Compliant }\end{array}$ & $\begin{array}{c}\text { Not } \\
\text { Compliant }\end{array}$ \\
\hline 10 & $\begin{array}{l}\text { Not } \\
\text { Compliant }\end{array}$ & Compliant & $\begin{array}{l}\text { Not } \\
\text { Compliant }\end{array}$ & $\begin{array}{l}\text { Not } \\
\text { Compliant }\end{array}$ & $\begin{array}{l}\text { Not } \\
\text { Compliant }\end{array}$ & $\begin{array}{l}\text { Not } \\
\text { Compliant }\end{array}$ & $\begin{array}{l}\text { Not } \\
\text { Compliant }\end{array}$ & $\begin{array}{l}\text { Not } \\
\text { Compliant }\end{array}$ \\
\hline 11 & Compliant & $\begin{array}{c}\text { Not } \\
\text { Compliant }\end{array}$ & Compliant & Compliant & $\begin{array}{c}\text { Not } \\
\text { Compliant }\end{array}$ & Compliant & Compliant & Compliant \\
\hline 12 & $\begin{array}{c}\text { Not } \\
\text { Compliant }\end{array}$ & $\begin{array}{c}\text { Not } \\
\text { Compliant }\end{array}$ & $\begin{array}{c}\text { Not } \\
\text { Compliant }\end{array}$ & $\begin{array}{c}\text { Not } \\
\text { Compliant }\end{array}$ & $\begin{array}{c}\text { Not } \\
\text { Compliant }\end{array}$ & $\begin{array}{c}\text { Not } \\
\text { Compliant }\end{array}$ & $\begin{array}{c}\text { Not } \\
\text { Compliant }\end{array}$ & $\begin{array}{c}\text { Not } \\
\text { Compliant }\end{array}$ \\
\hline 13 & $\begin{array}{c}\text { Not } \\
\text { Compliant }\end{array}$ & $\begin{array}{c}\text { Not } \\
\text { Compliant }\end{array}$ & $\begin{array}{c}\text { Not } \\
\text { Compliant }\end{array}$ & $\begin{array}{c}\text { Not } \\
\text { Compliant }\end{array}$ & Compliant & $\begin{array}{c}\text { Not } \\
\text { Compliant }\end{array}$ & $\begin{array}{l}\text { Not } \\
\text { Compliant }\end{array}$ & Compliant \\
\hline 14 & Compliant & Compliant & $\begin{array}{c}\text { Not } \\
\text { Compliant }\end{array}$ & Compliant & Compliant & Compliant & Compliant & Compliant \\
\hline 15 & $\begin{array}{c}\text { Not } \\
\text { Compliant }\end{array}$ & $\begin{array}{c}\text { Not } \\
\text { Compliant }\end{array}$ & $\begin{array}{c}\text { Not } \\
\text { Compliant }\end{array}$ & $\begin{array}{c}\text { Not } \\
\text { Compliant }\end{array}$ & $\begin{array}{c}\text { Not } \\
\text { Compliant }\end{array}$ & Compliant & Compliant & Compliant \\
\hline \multicolumn{9}{|c|}{ CorrectPrediction (\%) } \\
\hline Compliant & $100 \%$ & $100 \%$ & $100 \%$ & $100 \%$ & $100 \%$ & $100 \%$ & $87 \%$ & $93 \%$ \\
\hline $\begin{array}{c}\text { Not } \\
\text { Compliant } \\
\end{array}$ & $100 \%$ & $100 \%$ & $100 \%$ & $100 \%$ & $100 \%$ & $100 \%$ & $93 \%$ & $100 \%$ \\
\hline
\end{tabular}

*Format tampilan tabel dicontoh dari Ozkan-Gunay dan Ozkan (2007)

Model ANN lebih menekankan kepada kemampuan melakukan prediksi dengan meminimalisasi tingkat kesalahan yang sekecil-kecilnya, bukan menenkankan kepada kemampuan memberikan penjelasan pada model. Hingga saat ini, walaupun model tersebut diyakini sangat baik dalam memprediksi, masih menjadi misteri penentuan jumlahhidden layerdan perceptron atas seperangkat data yang ingin diprediksi hasilnya, sehingga model tidak mengindikasikan apapun berkaitan dengan jumlah hidden layerdan perceptronyang dipilih dalam model ANN yang dibentuk. Meskipun demikian, analisis tetap dilakukan dalam pembentukan model yang ideal. Dengan memperhitungkan karakteristik data time series, data diujikan secara berkala dan berulang-ulang dari tahun yang lampau sampai tahun berjalan dengan menghilangkan tahun-tahun terbarunya. Proses ini dilakukan secara berulang-ulang dengan berbagai macam simulasi dari data yang dimiliki sehingga terbentuk model ideal sebagaimana hasil prediksi pada Tabel 2 di atas.

Secara umum, model mampu memprediksi tingkat kepatuhan atas kondisi internal dan eksternal perbankan pada awal periode penelitian (2007-2012) secara sempurna, namum pada dua tahun terakhir penelitian (2013-2014) prediksi mengalami penurunan hingga nilai $87 \%$ untuk kategori compliant. Meskipun demikian model masih tetap 
mampu mempredeksi hingga mencapai ketepatan 100\% pada tahun 2014 untuk kategori not compliant. Hasil ini merupakan simulasi terbaik yang telah dilakukan dengan tetap memperhatikan kesederhanaan model yang dibentuk (tidak berlebihan dalam menentukan jumlah hidden layer dan percepton).

Model ANN yang telah dibentuk sangat memungkinkan untuk dilakukan evaluasi mengingat keterbatasan input dan waktu simulasi yang dimiliki, sehingga bukan tidak mungkin model tersebut kedepannya mengalami pengembangan yang lebih baik lagi. Namun, setidaknya model awal yang dibentuk dapat dijadikan acuan dalam penentuan model ANN lainnya guna didapatkan tingkat akurasi yang lebih baik dalam menditeksi potensi kegagalan suatu bank akibat adanya guncangan internal dan eksternal.

\section{Simpulan dan Saran}

Pada saat ini telah berkembang berbagai metodologi yang dapat digunakan oleh regulator untuk mendeteksi ketidakstabilan sistem keuangan mulai dari Discriminant analysis, Bayesian Model Average (BMA), KMV sampai Artifical Neural Network (ANN). Berdasarkan penelitian yang telah dilakukan oleh penulis Artifical Neural Network (ANN) dapat menjadi alternatif model sistem peringatan dini (early warning system) dalam mengetahui ketahanan perbankan atas guncangan faktor internal dan eksternal. Pada penelitian selanjutnya perlu dikaji kembali variabel kegagalan bank agar pendeteksian ketidakstabilan bank dapat dengan tepat terdeteksi.

\section{Daftar Pustaka}

Aini, Nur. (2013). Pengaruh CAR, NIM, LDR, NPL, BOPO, dan Kualitas Aktiva Produktif terhadap Perubahan Laba (Studi Empiris Pada Perusahaan Perbankan yang terdaftar di BEI) Tahun 2009-2011. Dinamika Akuntansi, Keuangan dan Perbankan, II (1): 14-25. ISSN :1979-4878.

Alawode, Abayomi A., Mohammed Al Sadek. (2008). What is Financial Stability?. Financial Stability Paper Series, No. 1. (http://www.cbb.gov.bh/ assets/FSP/What\%20is\%20Financial\%20Stability.pdf diakses pada tanggal 18 September 2015).

Bank Indonesia. (2015). Kajian Stabilitas Keuangan. http://www.bi.go.id/id/publikasi/perbankan-dan-stabilitas/kajian/ Documents/KSK_24_Maret\%202014.pdf, diakses pada tanggal 29 Agustus 2015).

Bank for International Settelement. (2004). International Convergence of Capital Measurement and Capital Standards A Revised Framework (http://www.federalreserve.gov/boarddocs/press/bcreg/2004/20040626/ attachment.pdf, diakses pada tanggal 7 Agustus 2015).

Fitri, Yudarsi Eka, Kamaludin dan Paulus Suluk Kananlua. (2012). Analisis Tingkat Kesehatan Bank dengan Sistem Risk Base Bank Rating (RBBR): Aplikasinya pada PT Bank Bengkulu. The Manager Review, XIII (2): 138-149. .ISSN 1979-2239.

Hosni, Khaoula. (2014). Early Warning Indicators for Systemic Banking Crises. Journal of Business Studies Quarterly, V (4): 222-244. ISSN 2152-1034.

Huang, Feixue, Yue Sheng, dan Zhijie Li. (2010). Evaluation of Default Risk Based on KMV Model for ICBC, CCB and BOC. International Journal of Economics and Finance, II (1): 7280.

Lampiran SE BI 13/24/DPNP Tahun 2011 tentang Penilaian Tingkat Kesehatan Bank. (http://www.ojk.go.id/Files/regulasi/perbankan/se-bi/2011/ lampiranI_se132411.pdf diakses pada tanggal 28 Juli 2015). 
Lasta, Heidy Arrvida, Zainul Arifin dan Nila Firdausi Nuzula. (2014). Analisis Tingkat Kesehatan Bank dengan Menggunakan Pendekatan RGEC (Risk Profile, Goode Corporate Governance, Earnings, Capital) Studi pada PT BRI, Tbk. Periode 20112013.Jurnal Administrasi Bisnis, XIII(2): 1-10.

Novaly, Rushans. (2014). Menjaga Sistem Keuangan Agar Tetap Stabil, Sebuah Sistem Terpadu. http:// www.kompasiana.com/rushanovaly/menjaga-sistem-keuangan-agar-tetapstabil-sebuah-sistem-terpadu_54f96768a33311ac048b4f19 diakses pada tanggal 7 September 2015.

Peraturan Bank Indonesia No 13/1/PBI Tahun 2011 tentang Penilaian Tingkat Kesehatan Bank Umum. http://www.bi.go.id/id/peraturan/perbankan/ Documents/828aa23594154a89aeabab7dc3103805pbi_130112.pdf, diakses pada tanggal 28 Juli 2015.

Purba, Bonaraja. (2013). Analisis Pengaruh Pertumbuhan PDB, Suku Bunga, IHK, Cadangan Devisa, dan Nilai Tukar Rupiah terhadap Pertumbuhan Jumlah Uang Beredar di Indonesia. Jurnal Saintech, V(1): 17-26.ISSN: 2086-9681.

Purnamasari, Ni Kadek Ita dan Ni Putu Sri Harta Mimba. (2014). Penilaian Tingkat Kesehatan PT. BPD BALI Berdasarkan Risk Profile, GCG, Earning, Capital. E-Jurnal Akuntansi Universitas Udayana, VII(3): 716-732. ISSN: 2302-8556.

Santoso, Wimboh dan Sukarela Batunanggar. (2008). Effective Financial System Stability Framework. Occasional Papers of The South East Asian Central Bank Research and Training Centre (The SEACEN Centre) (http://www.seacen.org/GUI/pdf/publications/occasional/2007/OP45.pdf diakses pada tanggal 18 September 2015).

Sekmen, Fuad dan Murat Kurkcu. (2014). An Early Warning System for Turkey: The Forecasting of Economic Crisis by Using The Artifical Neural Networks. Asian Economic and Finacial Review, IV(4): 529-543.

Sitompul, Willy. (2014). Mewujudkan Stabilitas Sistem Keuangan, Apa yang Perlu Kita Ketahui?. http://www.kompasiana.com/willysitompul/ mewujudkan-stabilitassistem-keuangan-apa-yang-perlu-kita-ketahui_54f3d2bb7455139f2b6c8101.

Sutono dan Batista Sufa Kefi. (2013). Pengaruh Faktor Makroekonomi terhadap Penghimpunan Dana pada Bank Umum di Indonesia. Jurnal Ekonomi Manajemen Akuntansi, XX (34): 1-12. ISSN 0853 - 8778.

Ozkan-Gunay, E. Nur dan Mehmed Ozkan. (2007). Prediction of bank failures in emerging financial markets: an ANN approach. The Journal of Risk Finance, VIII(5): 465-480.

Todorovic, Violeta. (2013). Alternative Regulatory Approaches to Managing Banking Crises. Economic Horizons, XV (3): 217-231. eISSN 2217-9232.

Yang, Bill Huajian dan Mykola Tkachenko. (2012). Modeling Exposure at Default and Loss Given Default: Empirical Approaches and Technical Implementation. The Journalof Credit Risk, VIII(2): 81-102. 